\title{
An Ultrafast Lithium-ion Battery with Long-term Cycling Performance Based on Hard Carbon
}

\author{
Manqin Tang ${ }^{1}$, Dan Zhao ${ }^{2}$, Jing Li $^{1, *}$, Pengyu Li $^{1}$, Jidong Duan ${ }^{1}$, Rui Wang ${ }^{1}$, Jinhan Teng ${ }^{1}$, \\ Chun Yuan ${ }^{3}$ \\ ${ }^{1}$ State Key Laboratory of Environmentally Friendly Energy Materials, School of Materials, Science \\ and Engineering, Southwest University of Science and Technology, Mianyang 621010, China. \\ ${ }^{2}$ Sichuan Lvxin Power Technology Co. Ltd, Suining 629000, China. \\ ${ }^{3}$ Gansu Jinchuan Group co. Ltd, Jinchang, 737100, China \\ *E-mail: xy13787103391@126.com
}

doi; $10.20964 / 2021.04 .57$

Received: 4 Janaury 2021 / Accepted: 17 February 2021 / Published: 28 February 2021

In this work, we construct lithium-ion batteries (LIBs) with capacitive-level cycling performance and ultrafast charge/discharge via electrode engineering. Two typical battery-type materials are used, namely, $\mathrm{LiNi}_{0.6} \mathrm{Co}_{0.2} \mathrm{Mn}_{0.2}$ as the cathode material and hard carbon (HC) without pre-lithiation as the anode material. In addition to the reasonable electrode design, it is concluded after analysing the energy storage mechanism that the capacitive-controlled storage behaviour of HC materials in a full cell configuration is the major reason that the device exhibits superior cycling performance. By conducting a galvanostatic charge/discharge cycling test of a $144 \mathrm{mAh}$ battery at $10 \mathrm{C}$ ( $\mathrm{t}_{\text {charge }} / \mathrm{t}_{\text {discharge }} \approx 4.8 \mathrm{~min}$ ), the capacity retention rate of the battery is $99.36 \%$ after 32000 cycles. The specific energy reaches 43.59 $\mathrm{Wh} \cdot \mathrm{kg}^{-1}$ at $42.01 \mathrm{~W} \cdot \mathrm{kg}^{-1}$ within a discharge time of $67.3 \mathrm{~s}$, while the energy density is $29.55 \mathrm{Wh} \cdot \mathrm{kg}^{-1}$ at $1580.81 \mathrm{~W} \cdot \mathrm{kg}^{-1}$; these values are calculated based on the weight of the whole device. This work expands the application range of $\mathrm{HC}$ materials in the field of batteries.

Keywords: lithium-ion battery, hard carbon, cycle life, $\mathrm{LiNi}_{0.6} \mathrm{Co}_{0.2} \mathrm{Mn}_{0.2}$, ultra-fast charge/discharge

\section{$\underline{\text { FULL TEXT }}$}

(C) 2021 The Authors. Published by ESG (www.electrochemsci.org). This article is an open access article distributed under the terms and conditions of the Creative Commons Attribution license (http://creativecommons.org/licenses/by/4.0/). 